\title{
Efficacy of repeated PSMA PET-directed radiotherapy for oligorecurrent prostate cancer after initial curative therapy
}

\author{
Christoph Henkenberens ${ }^{1} \mathbb{D}$ - Ann-Kathrin Oehus ${ }^{1} \cdot$ Thorsten Derlin $^{2}$ - Frank Bengel ${ }^{2}$ - Tobias L. Ross ${ }^{2}$. \\ Markus A. Kuczyk ${ }^{3}$. Stefan Janssen ${ }^{4,5}$ • Hans Christiansen ${ }^{1}$. Christoph A. J. von Klot ${ }^{3}$
}

Received: 21 February 2020 / Accepted: 25 April 2020 / Published online: 12 May 2020

(c) The Author(s) 2020

\begin{abstract}
Purpose To assess the outcome of prostate cancer (PCa) patients diagnosed with oligorecurrent disease and treated with a first and a second PSMA (prostate-specific membrane antigen ligand) PET(positron-emission tomography)-directed radiotherapy (RT).

Patients and methods Thirty-two patients with oligorecurrent relapse after curative therapy received a first PSMA PET-directed RT of all metastases. After biochemical progression, all patients received a second PSMA PET-directed RT of all metastases. The main outcome parameters were biochemical progression-free survival (bPFS) and androgen deprivation therapy-free survival (ADT-FS). The intervals of BPFS were analyzed separately as follows: the interval from the last day of PSMA PET-directed RT to the first biochemical progression was defined as bPFS_1 and the interval from second PSMA PET-directed RT to further biochemical progression was defined as bPFS_2.

Results The median follow-up duration was 39.5 months (18-60). One out of 32 (3.1\%) patients died after 47 months of progressive metastatic prostate cancer $(\mathrm{mPCa})$. All patients showed biochemical responses after the first PSMA PET-directed RT and the median prostate-specific antigen (PSA) level before RT was $1.70 \mathrm{ng} / \mathrm{mL}(0.2-3.8)$, which decreased significantly to a median PSA nadir level of $0.39 \mathrm{ng} / \mathrm{mL}$ (range $<0.07-3.8 ; p=0.004$ ). The median PSA level at biochemical progression after the first PSMA PET-directed RT was $2.9 \mathrm{ng} / \mathrm{mL}$ (range $0.12-12.80 ; p=0.24$ ). Furthermore, the PSA level after the second PSMA PET-directed RT at the last follow-up $(0.52 \mathrm{ng} / \mathrm{mL}$, range $<0.07-154.0)$ was not significantly different $(p=0.36)$ from the median PSA level $(1.70 \mathrm{ng} / \mathrm{mL}$, range $0.2-3.8)$ before the first PSMA PET-directed RT. The median bPFS_1 was 16.0 months after the first PSMA PET-directed RT (95\% CI 11.9-19.2) and the median bPFS_2 was significantly shorter at 8.0 months (95\% CI 6.3-17.7) after the second PSMA PET-directed RT ( $p=0.03$; 95\% CI 1.9-8.3). Multivariate analysis revealed no significant parameter for bPFS_1, whereas extrapelvic disease was the only significant parameter $(p=0.02$, OR $2.3 ; 95 \%$ CI 0.81-4.19) in multivariate analysis for bPFS_2. The median ADT-FS was 31.0 months (95\% CI 20.1-41.8) and multivariate analysis showed that patients with bone metastases, compared to patients with only lymph node metastases at first PSMA PET-directed RT, had a significantly higher chance $(p=0.007$, OR $4.51 ; 95 \%$ CI 1.8-13.47) of needing ADT at the last follow-up visit.

Conclusion If patients are followed up closely, including PSMA PET scans, a second PSMA PET-directed RT represents a viable treatment option for well-informed and well-selected patients.
\end{abstract}

Keywords PSMA $\cdot$ Biochemical progression $\cdot$ Metastatic Prostate cancer $\cdot$ Oligometastases $\cdot$ Radio-oncology

Availability of data and material All data and material are available upon justified request.

PD Dr. med. Christoph Henkenberens

henkenberens.christoph@mh-hannover.de

1 Department of Radiotherapy and Special Oncology, Hannover Medical School, Carl-Neuberg-Str. 1, 30625 Hannover, Germany

2 Department of Nuclear Medicine, Hannover Medical School, Carl-Neuberg-Str. 1, 30625 Hannover, Germany
3 Department of Urology and Urologic Oncology, Hannover Medical School, Carl-Neuberg-Str. 1, 30625 Hannover, Germany

4 Medical practice for Radiotherapy and Radiation Oncology, Treibesstraße 11, 31134 Hildesheim, Germany

5 Department of Radiation Oncology, University of Lübeck, Ratzeburger Allee 160, 23562 Lübeck, Germany 


\section{Introduction}

The cornerstone of treatment for non-castrated metastatic prostate cancer $(\mathrm{mPCa})$ is androgen deprivation therapy (ADT), which has remained unchanged over the past years [1]. The negative impact of ADT on quality of life (QoL) [1] has resulted in a search for alternatives for well-selected patients using personalized treatment concepts on the basis of prostate-specific membrane antigen ligand positronemission tomography (PSMA PET) [2-5]. There is increasing evidence that patients with a limited number of metastases have a better prognosis than patients with widespread metastatic disease, and data outside large prospective trials suggest that metastasis-directed therapies (MDTs) for mPCa patients with a so-called "oligometastatic status," based on a generally accepted imaging-based cut-off of five metastases, improve the clinical outcome [2, 6]. The recent introduction of PSMA ligand PET has substantially improved the diagnostic accuracy of staging at low prostatespecific antigen (PSA) levels [7-11], allowing refined and well-monitored individualized radio-oncological treatment concepts that aim to improve PSA kinetics, prolong progression-free survival, defer the initiation of ADT, and potentially cure the patient $[2-5,12]$. The STOMP [13] and POPSTAR trials [14], as well as the data published by Kneebone et al. [15], demonstrated that MDT alone might delay ADT for a relevant period. However, approximately half of the patients will develop oligoprogressive disease after MDT [13], making these patients amenable to repeated MDT and further improving the PSA kinetics and delaying the initiation of ADT [16]. Data on the feasibility and clinical outcome of a second MDT guided by PSMA PET imaging after previous PSMA PET-directed radiotherapy (RT) are very limited.

Thus, in the current study, we assessed the outcomes of patients with $\mathrm{mPCa}$ diagnosed with oligorecurrent disease after initial curative therapy who were treated with a second PSMA PET-directed radiotherapy (RT).

\section{Patients and methods}

Between June 2014 and February 2019, 32 hormone-naïve patients with oligorecurrent $\mathrm{PCa}$ after primary curative therapy received a first PSMA PET-directed RT as MDT for all metastases, and after oligoprogression, the patients received a definitive second PSMA PET-directed RT for all metastases. This retrospective study was approved by the local ethics committee (no. 3661-2017), and all cases were discussed and approved for RT by the multidisciplinary urooncologic board. Oligometastatic disease was defined as $\leq 5$ visceral, bone, or lymph node metastases. The patients' characteristics are summarized in Table 1.
Table 1 Patient characteristics

\begin{tabular}{|c|c|}
\hline Characteristics & $\begin{array}{l}\text { Median (range); } n \\
(\%)\end{array}$ \\
\hline Age at PCa diagnosis (years) & $63(53-74)$ \\
\hline Initial PSA $(n g / m l)$ & $9.8(3.7-47.4)$ \\
\hline \multicolumn{2}{|l|}{ Primary therapy } \\
\hline RPE alone & $11(34.4)$ \\
\hline $\mathrm{RPE}+\mathrm{aRT}$ & $9(28.1)$ \\
\hline $\mathrm{RPE}+\mathrm{sRT}$ & $10(31.2)$ \\
\hline EBRT + temporary ADT & $2(6.3)$ \\
\hline $\mathrm{cT} 1 \mathrm{c}$ & $2(6.3)$ \\
\hline pT2c & $13(40.6)$ \\
\hline pT3a & $4(12.5)$ \\
\hline pT3b & $12(37.5)$ \\
\hline pT4 & $1(3.1)$ \\
\hline \multicolumn{2}{|l|}{ Initial $N$ stage } \\
\hline No & $28(87.5)$ \\
\hline N1 & $4(12.5)$ \\
\hline \multicolumn{2}{|l|}{ Surgical margins } \\
\hline R0 & $28(93.3)$ \\
\hline $\mathrm{R} 1$ & $2(6.7)$ \\
\hline \multicolumn{2}{|l|}{ Initial risk group } \\
\hline High & $19(59.4)$ \\
\hline Very high & $13(40.6)$ \\
\hline Initial PSA (ng/ml) & $9.8(3.7-47.4)$ \\
\hline PSA nadir after definitive therapy $(\mathrm{ng} / \mathrm{ml})$ & $0.07(<0.07-3.0)$ \\
\hline $\begin{array}{l}\text { Interval (months) from definitive therapy to } \\
\text { PSMA PET }\end{array}$ & $47(12-168)$ \\
\hline PSA level at PSMA-PET imaging $(\mathrm{ng} / \mathrm{ml})$ & $1.70(0.2-4.8)$ \\
\hline $\begin{array}{l}\text { Patients with ADT at PSMA-ligand PET } \\
\text { imaging }\end{array}$ & $0(\%)$ \\
\hline $\begin{array}{l}\text { Median PSA-dt at time of PSMA-PET imag- } \\
\text { ing (months) }\end{array}$ & $8.7(3.1-17.2)$ \\
\hline$<6$ & $7(21.9)$ \\
\hline$>6,<12$ & $10(31.2)$ \\
\hline$>12$ & $15(46.9)$ \\
\hline
\end{tabular}

$A D T$ androgen deprivation therapy, $a R T$ adjuvant radiotherapy, $d t$ doubling time, EBRT external beam radiation therapy, $P C a$ prostate cancer, PSMA-PET prostate-specific membrane antigen positronemission tomography, $P S A$ prostate-specific antigen, $R P$ radical prostatectomy, $s R T$ salvage radiotherapy

\section{PET imaging}

Each patient received PET imaging with a ${ }^{68}$ gallium-labeled PSMA ligand [17] and imaging was performed according to the joint EANM and SNMMI guidelines [18]. PSMA PET scans were acquired in conjunction with lowdose computed tomography (CT) on a dedicated PET/CT system (Siemens Biograph mCT 128 Flow; Siemens, Knoxville, TN, USA) equipped with an extended fieldof-view lutetium oxyorthosilicate PET component, a 128slice spiral CT component, and a magnetically powered table optimized for continuous scanning. No intravenous 
contrast material was administered. All patients gave written informed consent before PSMA PET/CT. A positive visual assessment of increased focal tracer uptake higher than the surrounding background activity was used as the criterion for malignancy [9].

\section{Radiotherapy treatment}

Patients with lymph node metastases or relapse in the prostatic fossa were treated with conventionally fractionated RT (CF-RT) and patients with bone metastases were treated with slightly hypofractionated RT (HF-RT). In the case of lymph node metastases, the clinical target volume (CTV) encompassed the lymph drainage vessel to the next bifurcation without the whole ipsilateral lymphatic drainage vessel; the dose was 50.0 Gy (single dose 2.0 Gy), followed by a sequential CF-RT boost of $10.0 \mathrm{~Gy}$ (single dose $2.0 \mathrm{~Gy}$ ) to the lymph node metastases. Relapse in the prostate bed was treated with CF-RT doses of 70.0-74.0 Gy (single dose of 2.0Gy). Bone metastases were treated with HF-RT and a single dose of $2.5 \mathrm{~Gy}$ up to a dose of $45.0 \mathrm{~Gy}$. The planning target volume (PTV) for lymph node metastases, bone metastases, and local relapse in the prostatic fossa included the CTV plus a $10-\mathrm{mm}$ safety margin in all directions to account for setup errors. Image guidance was conducted at least twice a week with megavoltage cone-beam CT. Visceral metastases were treated with image-guided stereotactic body radiation therapy (SBRT) and a total dose of $37.5 \mathrm{~Gy}$ (single dose $12.5 \mathrm{~Gy}$ ) to the encompassing $67 \%$ PTV isodose. The PTV included the internal target volume (ITV) plus a 4-mm safety margin in all directions to account for setup errors.

\section{Follow-up and endpoints}

All patients had periodic urologic follow-up evaluations, which included PSA measurements every 3 months. Biochemically progressive disease after RT was defined as two consecutive increases in PSA levels from the nadir PSA level or a PSA level above baseline. Biochemical nonresponse was defined as the first PSA level 3 months after RT that was $\geq 10 \%$ of the baseline PSA level at the time of PSMA PET/CT scan before RT. Patients who met the criteria of biochemical progression had a second PSMA PET/CT for restaging purposes, which was used for the second PSMA PET-directed RT to irradiate all new metastases. Patients with extensive disease ( $\geq 6$ metastases) received systemic therapy according to the urologist's choice. In general, outcomes were defined from the last day of RT. The outcome parameters were biochemical progression-free survival (bPFS), ADT-free survival (ADT-FS), overall survival (OS), and toxicity. The intervals of BPFS were analyzed separately as follows: the interval from the last day of first PSMA PET-directed RT to the first biochemical progression was defined as bPFS_1 and the interval from second PSMA PET-directed RT to further biochemical progression was defined as bPFS_2. RT-associated toxicity was analyzed using the National Cancer Institute Common Terminology Criteria for Adverse Events (CTCAE) v4.0 [19]. To assess the local failure rate we performed a coregistration of the PSMA PET/CT scans with the RT treatment plans. Focally increased tracer uptake higher than the surrounding background within the PTV was classified as infield relapse.

\section{Statistical analysis}

For statistical analysis, SPSS Statistics v25.0 (IBM, Armonk, New York, USA) was used. We used the paired Student's $t$-test to compare pre-RT with post-RT parametric parameters and the Wilcoxon signed-rank test when the data were not normally distributed. The time-to-event data were calculated using the Kaplan-Meier method. Factors for RT treatment failure were analyzed with the log rank test in univariate analyses and significant factors were further assessed with multivariate analyses to identify independent variables for bRFS and ADT-FS. $P$-values $<0.05$ were considered statistically significant. Graphical presentations of the patterns of progression were created using a free software for statistical computing and graphics ( $\mathrm{R}$ version 3.0.3).

\section{Results}

\section{PSMA PET staging and therapy for metastases}

A total of 59 PSMA ligand-positive metastases were detected and treated with RT. Of these, 66.1\% (39/59) were pelvic lymph node metastases, $5.1 \%$ (3/59) were periaortic lymph node metastases, $22.0 \%$ (13/59) were bone metastases, $1.7 \%(1 / 59)$ were visceral metastases, and $5.1 \%$ $(3 / 59)$ were local relapses in the prostatic fossa. A total of $53.1 \%$ of patients $(17 / 32)$ had only lymph node metastases, $31.3 \%$ (10/32) of patients had only bone metastases, $12.5 \%$ (4/32) of patients had lymph node and bone metastases, and $2.6 \%(1 / 32)$ of patients had visceral metastases.

\section{Patterns of progression and patient outcomes}

Table 2 summarizes the results of PSMA PET scans and first PSMA PET-directed RT, as well as the results from PSMA PET restaging after biochemical progression and a consecutive second PSMA PET-directed RT. Analysis of the RT treatment plans and the PSMA PET/CT scans for all metastases at first $(n=59)$ and second $(n=60)$ PSMA PET- 
Table 2 Results of PSMA ligand PET staging prior to PSMA ligand-based radiotherapy and PSMA ligand PET restaging prior to second PSMA ligand-based radiotherapy

\begin{tabular}{lll}
\hline & PSMA ligand-based RT & Second PSMA ligand-based RT \\
\hline No. of PSMA ligand-positive lesions & $N(\%)$ & $N(\%), p$-value \\
Total no. of LNs & $59(100)$ & $60(100) ; 0.90$ \\
...Pelvic LNs & $42(69.2)$ & $36(60) ; 0.51$ \\
...Periaortic/interaortocaval LNs & $39(36.2)$ & $15(25) ; 0.03$ \\
Total no. of bone metastases & $3(27.6)$ & $19(31.7) ; 0.09$ \\
$\ldots$. Pelvic bone & $13(24.3)$ & $23(38.3) ; 0.04$ \\
...Spinal bone & $7(13.0)$ & $10(16.7) ; 0.37$ \\
...Other & $4(5.4)$ & $11(18.3) ; 0.14$ \\
Prostatic fossa & $2(5.9)$ & $2(3.3) ; 0.64$ \\
Total no. of visceral metastases & $3(6.5)$ & $0(0) ; 0.32$ \\
Concurrent ADT at radiotherapy & $1(1.7)$ & $1(1.7) ; 0.91$ \\
Other local therapies (e.g., surgery, RFA) & $0(0.0)$ & $3(9.4) ; 0.32$ \\
& $0(0.0)$ & $0(0.0)$ \\
PSA before RT & Median (range) & Median (range); $p$-value \\
PSA-dt (months) & $1.71(0.21-3.8)$ & $2.90(0.12-22.80) ; 0.23$ \\
No. irradiated metastases & $8.7(3.1-17.2)$ & $5.8(1.6-8.2) ; 0.05$
\end{tabular}

$A D T$ androgen deprivation therapy, $d t$ doubling-time, $L N s$ lymph node metastases, $P C a$ prostate cancer, $P S M A$ - $P E T$ prostate-specific membrane antigen positron-emission tomography, $P S A$ prostate-specific antigen, $R F A$ radiofrequency ablation, $s R T$ salvage radiotherapy, $S B R T$ stereotactic body radiation therapy, $S I B$ simultaneous integrated boost

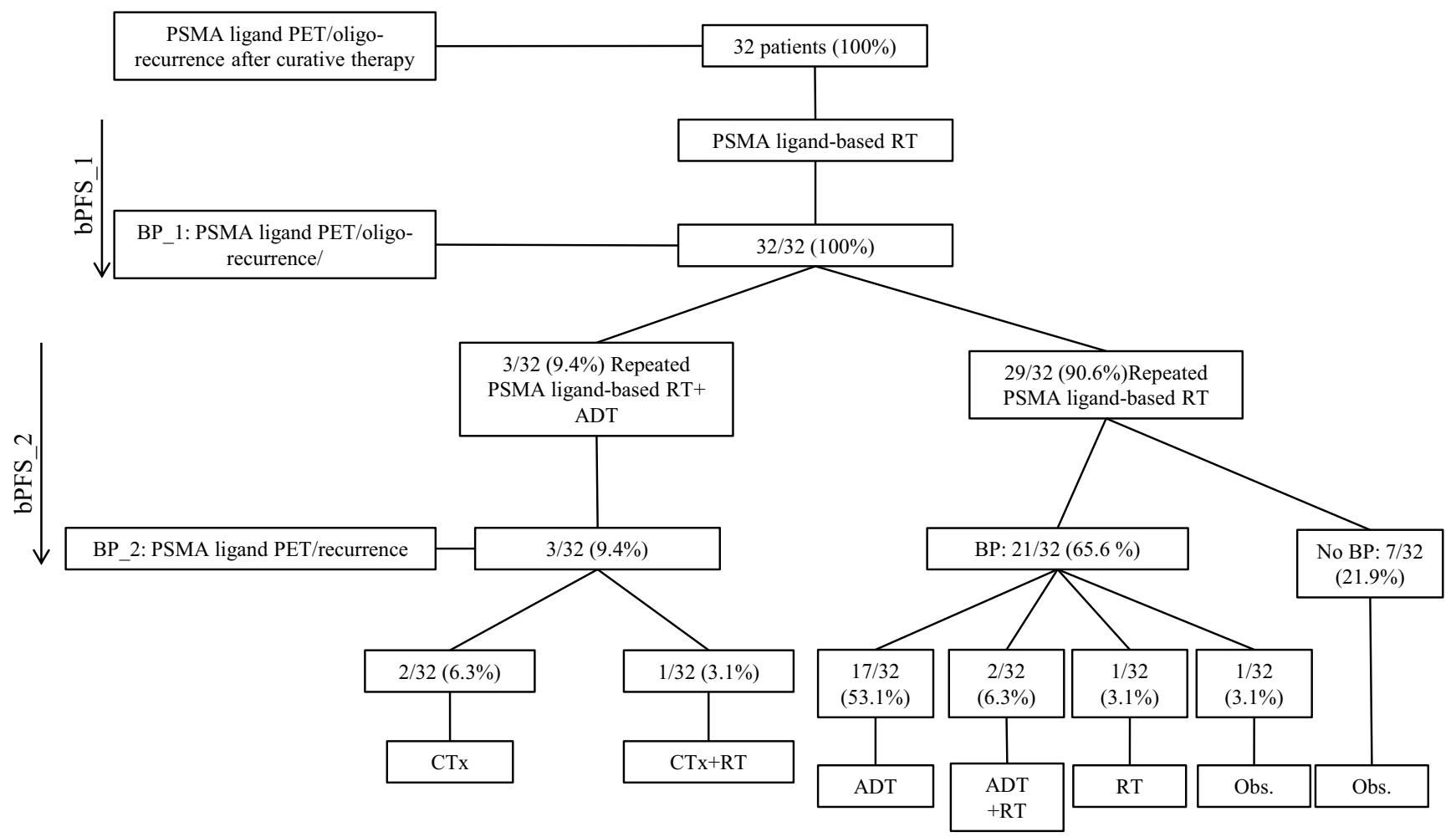

Fig. 1 Schematic overview of the treatment and relapse patterns of oligorecurrent prostate cancer after first and second PSMA PET-directed RT. $A D T$ androgen deprivation therapy, $B P$ biochemical progression, $B P \_1$ first biochemical progression, $B P \_2$ second biochemical progression, $b P F S \_1$ interval from last day of PSMA PET-directed RT to first biochemical progression, $b P F S \_2$ interval from second PSMA PET-directed RT to further/second biochemical progression, $C T$ chemotherapy, $O b s$ observation, PET positron-emission tomography, PSMA prostate-specific membrane protein, $R T$ radiotherapy 


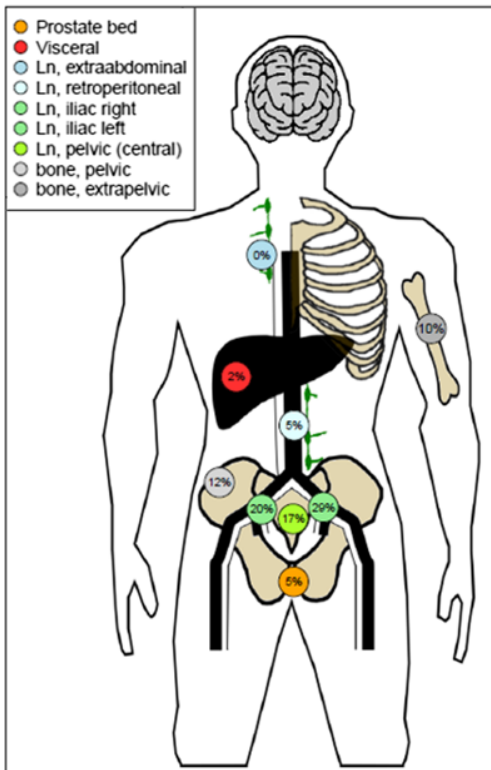

b

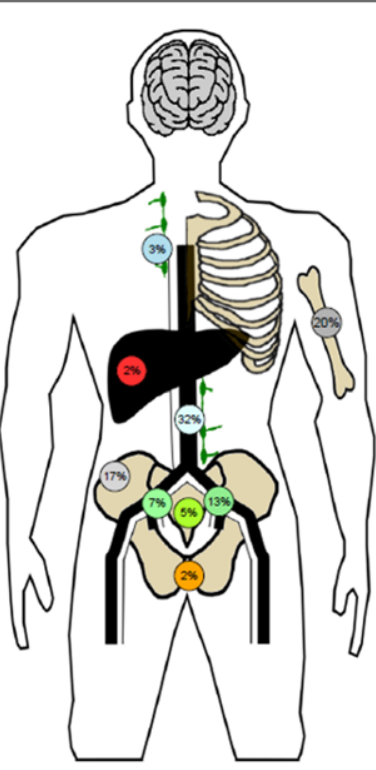

C

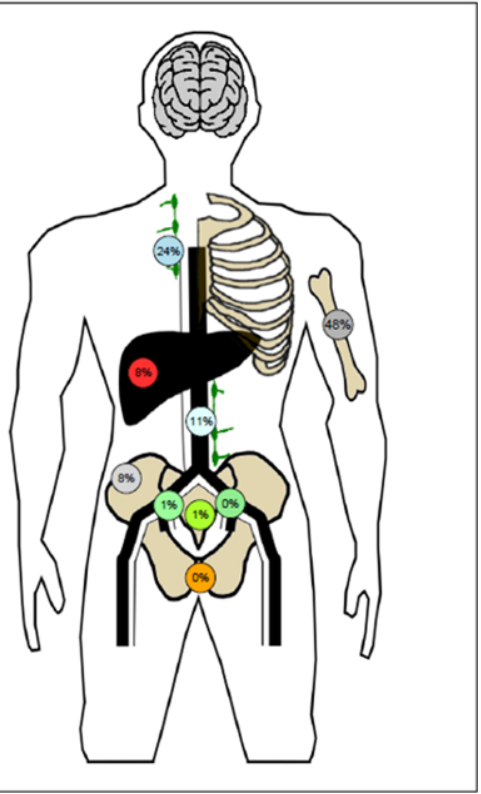

Fig. 2 Schematic illustration of the distribution of metastases at oligorecurrence based on PSMA PET/CT after curative initial therapy for prostate cancer (a), distribution of metastases at oligoprogression after first PSMA PET-directed RT (b) and distribution of metastases at further progression after second PSMA PET-directed RT (c) showing local control in the pelvis and the increase in extrapelvic lymph node and extrapelvic bone metastases. $L n$ lymph nodes

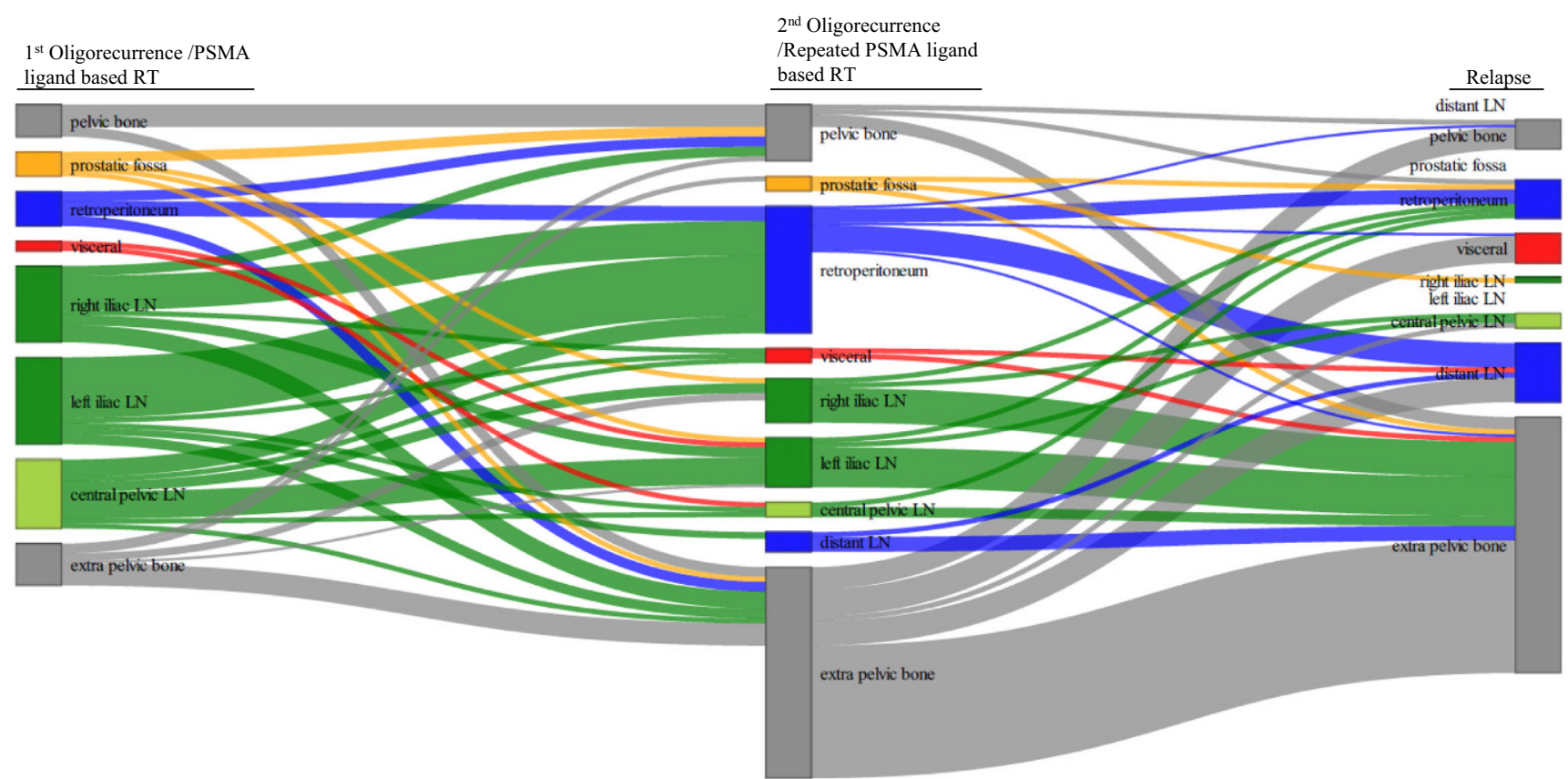

Fig. 3 Sankey plot showing the location of new metastases in relation to prior metastatic sites (for every patient, every metastatic lesion was counted). On the left side, the initial distribution at oligorecurrence at the time of first PSMA PET-directed RT is shown; in the middle, the distribution of metastases at the time of second PSMA PET-directed RT is shown; and on the right side, the distribution after second PSMA ligand-directed RT is shown. Similar to the analysis of the involved anatomic regions (Fig. 2), we observed a numerical shift from iliac lymph node metastases to retroperitoneal lymph node metastases and marked skeletal involvement, particularly involving the extrapelvic skeletal system. $P S M A$ prostate-specific membrane antigen, $R T$ radiotherapy, $L N$ lymph node 
Fig. 4 Kaplan-Meier curves of biochemical progression-free survival (bPFS) after first PSMA PET-directed radiotherapy (bPFS_1; a) and after second PSMA PET-directed radiotherapy $\left(b P F S \_2 ; \mathbf{b}\right)$

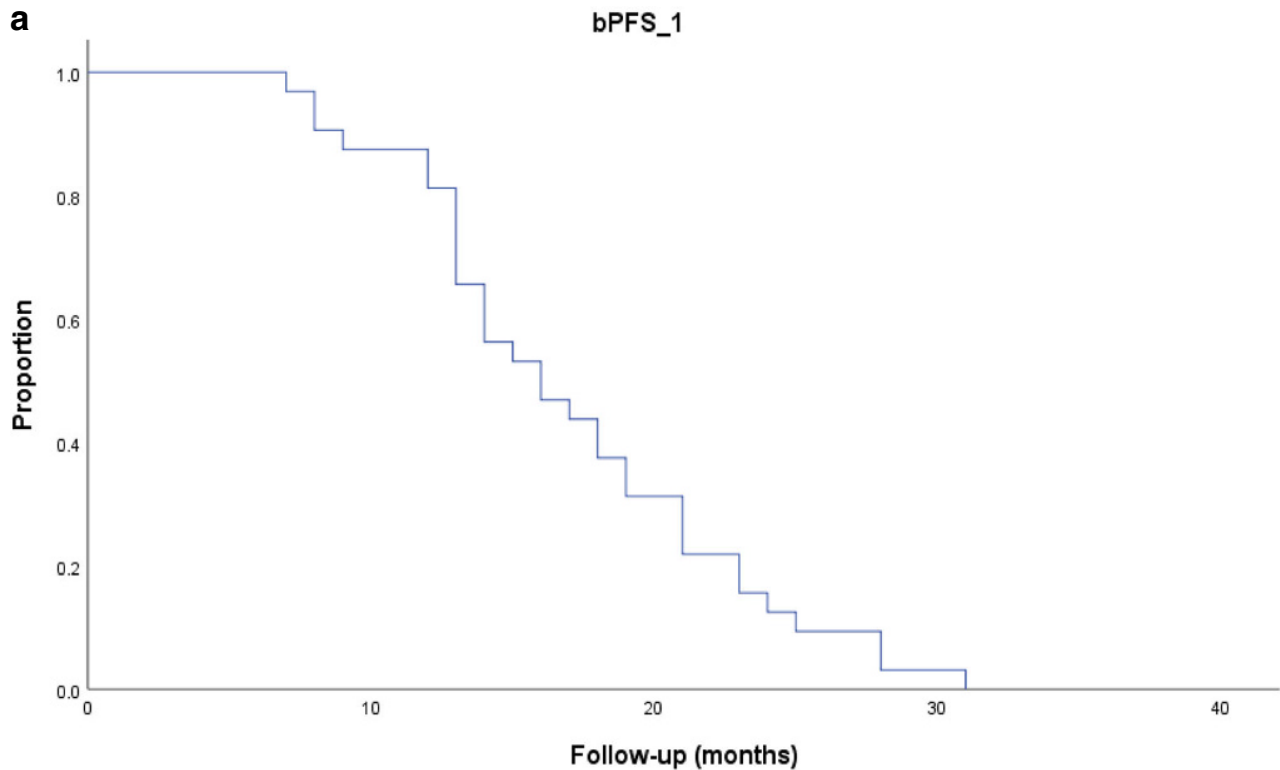

No. at risk:

32

28

12

2

0

b

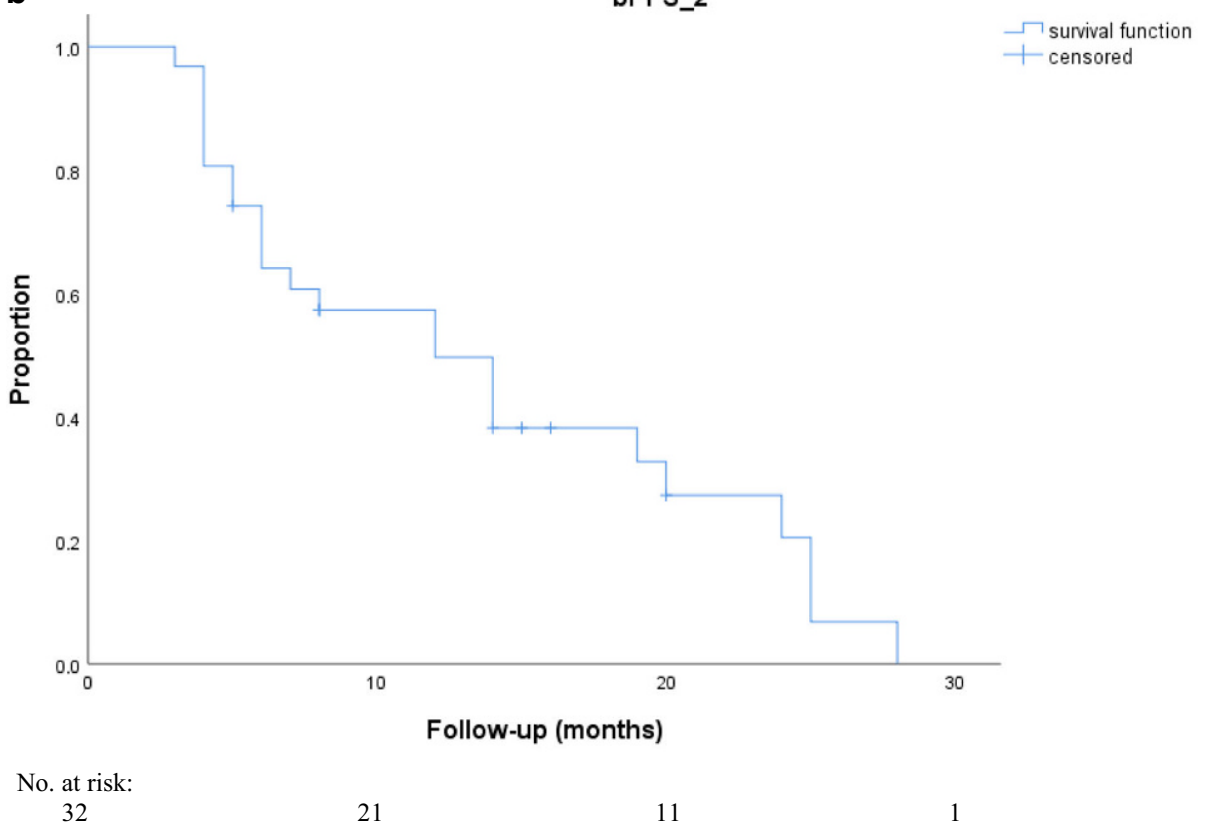

directed RT resulted in a cumulative infield relapse rate of $3.4 \%(4 / 119)$ and in a cumulative outfield relapse rate of $96.6 \%(115 / 119)$. The four infield relapses occurred in the right iliac lymph nodes $(25 \%, 1 / 4)$, in a rib metastasis $(25 \%$, $1 / 4)$, and in pelvic bone metastases $(50 \%, 2 / 4)$.

The median follow-up time was 39.5 months (18-60). One out of $32(3.1 \%)$ patients died after 47 months of progressive $\mathrm{mPCa}$. All patients showed biochemical responses after the first PSMA PET-directed RT: the median PSA level before first RT was $1.70 \mathrm{ng} / \mathrm{mL}(0.2-3.8)$, which decreased significantly to a median PSA nadir level of $0.39 \mathrm{ng} / \mathrm{mL}$ (range $<0.07-3.8 ; p=0.004$ ). The median PSA level at biochemical progression after the first PSMA PET-directed RT was $2.9 \mathrm{ng} / \mathrm{mL}$ (range $0.12-12.80$; $p=0.24$ ). Furthermore, the PSA level after the second PSMA PET-directed RT at the last follow-up $(0.52 \mathrm{ng} / \mathrm{mL}$, range $<0.07-154.0)$ was not significantly different $(p=0.36)$ from the median PSA level $(1.70 \mathrm{ng} / \mathrm{mL}$, range $0.2-3.8)$ before the first PSMA PET-directed RT. Additionally, $12.5 \%$ (4/32) of patients did not show a biochemical response after 
Table 3 Results of uni- and multivariate analyses for first and second biochemical progression-free survival (bPFS_1, bPFS_2)

\begin{tabular}{|c|c|c|c|c|}
\hline & \multicolumn{2}{|l|}{ bPFS_1 } & \multicolumn{2}{|l|}{ bPFS_2 } \\
\hline & $\begin{array}{l}\text { Univariate analysis } \\
p \text {-value }\end{array}$ & $\begin{array}{l}\text { Multivariable analysis } \\
p \text {-value, OR ( } 95 \% \mathrm{CI})\end{array}$ & $\begin{array}{l}\text { Univariate analysis } \\
p \text {-value }\end{array}$ & $\begin{array}{l}\text { Multivariable analysis } \\
p \text {-value, OR }(95 \% \mathrm{CI})\end{array}$ \\
\hline Initial $\mathrm{T}$ stage $(\leq \mathrm{T} 2 \mathrm{vs} . \geq \mathrm{T} 3)$ & 0.91 & - & 0.96 & - \\
\hline Initial N stage (N0 vs. N1) & 0.39 & - & 0.67 & - \\
\hline Initial PSA level in $\mathrm{ng} / \mathrm{ml}$ ( $\leq 20$ vs. $>20$ ) & 0.81 & - & 0.82 & - \\
\hline Initial PSA level in $\mathrm{ng} / \mathrm{ml}$ ( $\leq 10$ vs. $>10$ ) & 0.92 & - & 0.54 & - \\
\hline $\begin{array}{l}\text { PSA nadir after RP }(\leq 0.07 \mathrm{ng} / \mathrm{mL} \text { vs. } \\
>0.07 \mathrm{ng} / \mathrm{mL})\end{array}$ & 0.33 & - & 0.39 & - \\
\hline Gleason score ( $\leq 7$ vs. $\geq 8$ ) & 0.18 & - & 0.22 & - \\
\hline No. of removed LN at RP ( $\leq 15$ vs. $>15)$ & 0.63 & - & 0.34 & - \\
\hline $\begin{array}{l}\text { Initial risk group (high risk vs. very high } \\
\text { risk) }\end{array}$ & 0.32 & - & 0.54 & - \\
\hline PSA-dt (months; $\leq 6,>6$ ) & 0.02 & $\begin{array}{l}0.12,1.92 \\
(1.02-8.52)\end{array}$ & 0.19 & - \\
\hline PSA dt (months, $\leq 12,>12$ ) & 0.05 & $\begin{array}{l}0.23,1.76 \\
(0.34-8.71)\end{array}$ & 0.46 & - \\
\hline No. of irradiated metastases ( 1 vs. >1) & 0.73 & - & 0.19 & - \\
\hline No. of irradiated metastases ( $\leq 2$ vs. $\geq 3$ ) & 0.23 & - & 0.05 & $\begin{array}{l}0.56,0.73 \\
(0.29-1.28)\end{array}$ \\
\hline No. of irradiated metastases ( $\leq 3$ vs. $\geq 4$ ) & 0.24 & - & 0.20 & - \\
\hline Type of metastases (LNs vs. bone) & 0.45 & - & 0.04 & $\begin{array}{l}0.19,0.64 \\
(0.23-1.39)\end{array}$ \\
\hline Extrapelvic disease (LNs and/or bone) & 0.92 & - & 0.02 & $0.02,2.3(0.81-4.19)$ \\
\hline
\end{tabular}

$d t$ doubling time, $L N$ lymph node, $P S A$ prostate-specific antigen, $R P$ radical prostatectomy

Fig. 5 Kaplan-Meier curves of androgen deprivation therapy-free survival $(A D T-F S)$ after first and second PSMA ligand PET-directed radiotherapy

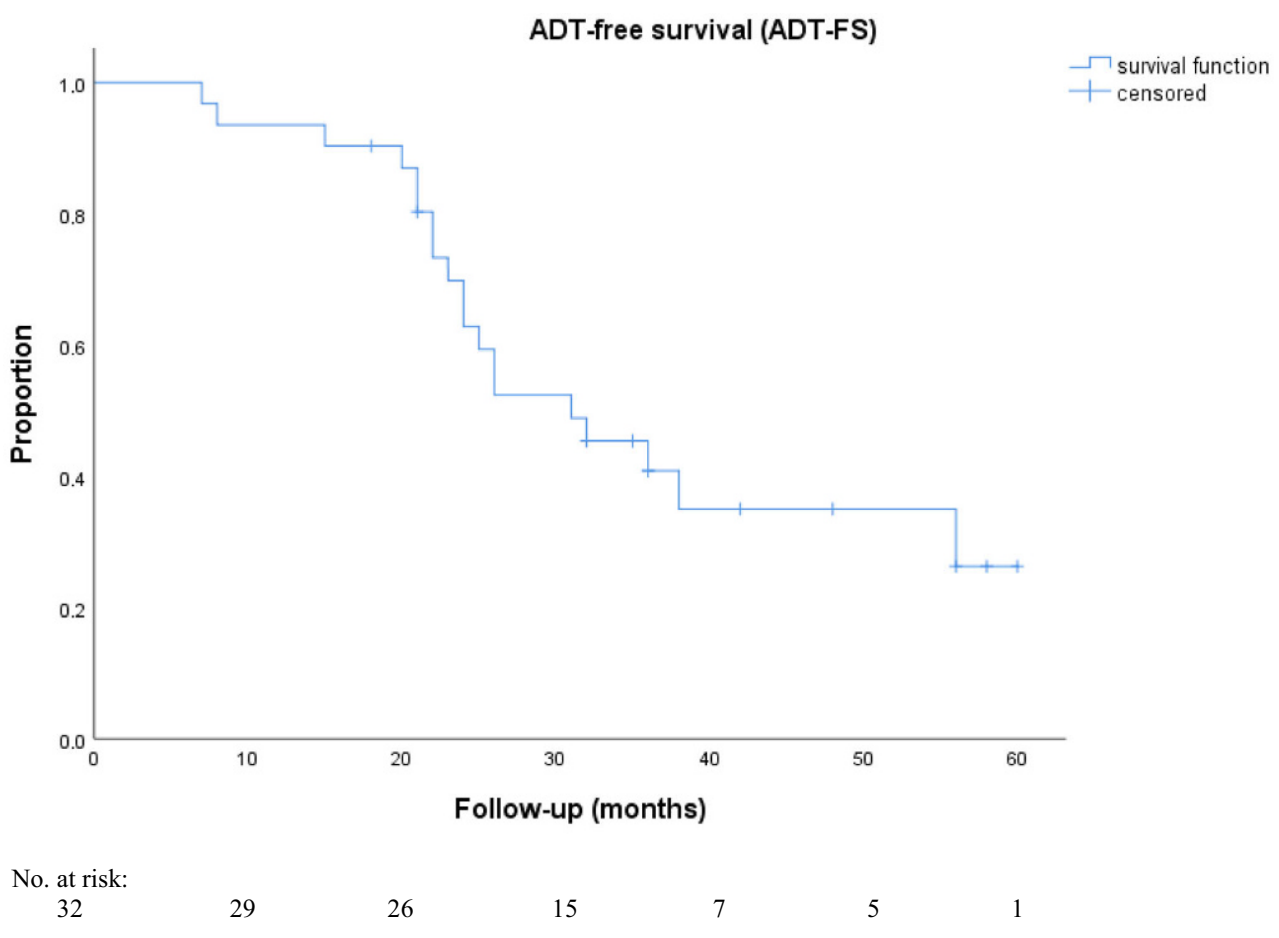

the initial distribution of metastases at the time of the first PSMA PET-directed RT and the location of new metastases at the time of the second PSMA PET-directed RT, as well 
Table 4 Results of uni- and multivariate analyses for androgen deprivation therapy-free survival (ADT-FS)

\begin{tabular}{|c|c|c|c|}
\hline & \multirow{2}{*}{$\begin{array}{l}\text { Univariate analysis } \\
p \text {-value }\end{array}$} & \multicolumn{2}{|c|}{ Multivariate analysis } \\
\hline & & $p$-value & OR, $(95 \% \mathrm{CI})$ \\
\hline Initial $\mathrm{T}$ stage $(\leq \mathrm{T} 2 \mathrm{vs} . \geq \mathrm{T} 3)$ & 0.19 & - & - \\
\hline Initial N stage (N0 vs. N1) & 0.66 & - & - \\
\hline Initial PSA level in $\mathrm{ng} / \mathrm{ml}(\leq 10$ vs. $>10)$ & 0.47 & - & - \\
\hline Initial PSA level in ng/ml ( $\leq 20$ vs. $>20$ ) & 0.50 & - & - \\
\hline PSA nadir after RP $(\leq 0.07 \mathrm{ng} / \mathrm{mL}$ vs. $>0.07 \mathrm{ng} / \mathrm{mL})$ & 0.97 & - & - \\
\hline Gleason score ( $\leq 7$ vs. $\geq 8$ ) & 0.10 & - & - \\
\hline No. of removed LNs at RP ( $\leq 15$ vs. $>15$ ) & 0.36 & - & - \\
\hline Initial risk group (high risk vs. very high risk) & 0.75 & - & - \\
\hline PSA-dt (months; $\leq 6,>6$ ) at first PSMA ligand-based RT & 0.01 & 0.74 & $1.25,0.34-4.60$ \\
\hline PSA-dt (months; $\leq 12,>12$ ) at first PSMA ligand-based RT & 0.13 & - & - \\
\hline PSA-dt (months; $\leq 6,>6$ ) at second PSMA ligand-based RT & 0.27 & - & - \\
\hline PSA-dt (months; $\leq 12,>12$ ) at second PSMA ligand-based RT & 0.87 & - & - \\
\hline No. of irradiated metastases ( 1 vs. $>1$ ) at first PSMA ligand-based RT & 0.81 & - & - \\
\hline $\begin{array}{l}\text { No. of irradiated metastases (no. of irradiated metastases }[\leq 2 \mathrm{vs.} \geq 3] \text { at first } \\
\text { PSMA ligand-based RT) }\end{array}$ & 0.27 & - & - \\
\hline $\begin{array}{l}\text { No. of irradiated metastases (no. of irradiated metastases }[\leq 3 \mathrm{vs.} \geq 4] \text { at first } \\
\text { PSMA ligand-based RT) }\end{array}$ & 0.05 & 0.59 & $1.68,0.35-6.02$ \\
\hline No. of irradiated metastases ( 1 vs. $>1$ ) at second PSMA ligand-based RT & 0.52 & - & - \\
\hline No. of irradiated metastases ( $\leq 2$ vs. $\geq 3$ ) at second PSMA ligand-based RT & 0.92 & - & - \\
\hline No. of irradiated metastases ( $\leq 3$ vs. $\geq 4$ ) at second PSMA ligand-based RT & 0.36 & - & - \\
\hline Type of metastases at first PSMA ligand-based RT (lymph node vs. bone) & $<0.001$ & 0.007 & $4.51,1.8-13.47$ \\
\hline Extrapelvic disease at first PSMA ligand-based RT (lymph node vs. bone) & 0.31 & - & - \\
\hline Type of metastases at second PSMA ligand-based RT (LN vs. bone) & 0.82 & - & - \\
\hline Extrapelvic disease at second PSMA ligand-based RT (LN and/or bone) & 0.01 & 0.03 & $3.2,1.2-15.10$ \\
\hline
\end{tabular}

$d t$ doubling time, $L N$ lymph node, $P S A$ prostate-specific antigen, $P S M A$ prostate-specific membrane antigen, $R P$ radical prostatectomy

as at the time of further progression after the second PSMA PET-directed RT.

The median bPFS_1 was 16.0 months after first PSMA PET-directed RT (95\% CI 11.9-19.2; Fig. 4a) and the median bPFS_2 was significantly shorter at 8.0 months $(95 \%$ CI 6.3-17.7; Fig. 4b) after second PSMA PET-directed RT $(p=0.03 ; 95 \%$ CI $1.9-8.3)$. None of the parameters significant for bPFS_1 in the univariate analyses reached significance in multivariate analyses. Extrapelvic disease was the only significant parameter $(p=0.02$, OR $2.3 ; 95 \%$ CI 0.81-4.19) in multivariate analysis for bPFS_2. Table 3 shows the detailed results of uni- and multivariate analyses for bPFS 1 and bPFS 2 .

At the last follow-up, $28.1 \%$ (9/32) of patients did not need ADT. The median ADT-FS was 31.0 months $(95 \%$ CI 20.1-41.8; Fig. 5) and multivariate analysis showed that patients with bone metastases, compared to patients with only lymph node metastases at the first PSMA PET-directed RT, had a significantly higher chance $(p=0.007$, OR 4.51; 95\% CI 1.8-13.47) of needing ADT at the last follow-up visit. Furthermore, patients with oligoprogression outside the pelvis, compared to patients with oligoprogression limited to the pelvis at the second PSMA PET-directed RT, also had a significantly higher risk of needing ADT at the last follow-up visit ( $p=0.03$, OR 3.2; 95\% CI 1.2-15.10). Table 4 shows the detailed results of uni- and multivariate analyses for ADT-FS.

\section{Toxicity}

Acute grade III toxicity was not observed; 3.1\% (1/32) of patients developed grade II acute genitourinary toxicity. Grade II acute gastrointestinal toxicity occurred in $12.5 \%$ (4/32) of patients and grade I acute gastrointestinal toxicity occurred in $9.4 \%(3 / 32)$ of patients. Late grade III gastrointestinal toxicity occurred in $3.1 \%(1 / 32)$ of patients and grade II genitourinary toxicity occurred in $3.1 \%(1 / 78)$ of patients.

\section{Discussion}

The implementation of PSMA ligand PET imaging has substantially improved the diagnostic accuracy of detecting metastatic PCa at low PSA levels [7, 8, 20]. Although large randomized prospective studies are lacking, MDT is considered a viable treatment option for well-selected patients with oligorecurrent PCa [21]. Furthermore, there is 
still controversy about the optimal timing to initiate palliative ADT for asymptomatic metastatic patients because of the lack of prospective trials in the PSA era [1]. Furthermore, ADT offers no curative potential [1] and significantly impairs QoL in a relevant number of patients [22].

Smaller prospective trials with heterogeneous patient cohorts, including one with choline PET imaging [13], one with PSMA ligand PET imaging [14], and one with sodium fluoride (NA-F) PET imaging [15], showed encouraging results for MDT in oligometastatic prostate cancer. The STOMP [13] and POPSTAR trials [14], as well as the data published by Kneebone et al. [15], demonstrated that MDT alone might delay ADT for a relevant period. However, patients with MDT alone develop biochemical progression earlier than patients with MDT plus ADT [13-15]. To the best of the authors' knowledge, there are no published data comparing MDT alone versus MDT plus ADT with regard to hard endpoints such as prostate carcinoma-specific survival. In our opinion, patients must be well informed that ADT is the standard of care and any type of MDT is an individual treatment concept outside the current guidelines, although the optimal timing of initiation of ADT at low PSA levels remains unknown [1]. Nevertheless, approximately half of the patients will develop oligoprogressive disease after MDT alone [7], making these patients amenable to a second MDT and further delaying the start of ADT [13, 23, 24]. Additionally, due to the lack of data from prospective trials, the current guidelines do not reflect the diagnostic accuracy of PSMA ligand PET staging at low PSA levels to select patients who should or should not receive ADT [1].

To the best of our knowledge, a second RT for oligorecurrent PCa on the basis of PSMA ligand PET staging and restaging has never been reported. We showed that $28.1 \%$ (9/32) of patients did not need ADT at the last follow-up, resulting in a median ADT-FS of 31.0 (95\% CI 20.1-41.8) months, which is approximately the same as the duration that other authors have reported [13, 23, 24]. None of the published data [13, 23, 24] included PSMA ligand PET staging for MDT that led to MDT at higher PSA levels, particularly increasing the likelihood that patients had an underestimated extent of lymph node metastases [11, 22]. In addition, the initiation of ADT based on the urologist's choice at low PSA levels might be a confounder for ADTFS and, therefore, hamper the comparison of these retrospective data.

We found that the type of irradiated metastases at oligorecurrence was the most important clinical parameter for ADT-FS. Patients with bone metastases had a significantly higher risk ( $p=0.007$, OR $4.51 ; 95 \%$ CI $1.8-13.47$ ) of needing ADT at their last follow-up compared to patients with only lymph node metastases. Population-based data supported our findings because patients with bone metastases have a worse prognosis and lower cancer-specific sur- vival (CSS) than those with lymph node metastases [25, 26]. A recently published SEER database analysis suggested that patients with stage M1a tumors receive significantly greater clinical benefits from local therapies to the prostate than patients with stage M1b tumors [27]. Although the median number of irradiated metastases per patient at the first PSMA PET-directed RT and at the second PSMA PET-directed RT was the same $(n=2 ; p=0.90)$, the median BPFS_2 after the second PSMA PET-directed RT was significantly shorter than the median BPFS_1 after the first PSMA PE-directed RT (8.0 months vs. 16.0 months, $p=0.03$; 95\% CI 1.9-8.3). Moreover, the shorter BPFS after the second PSMA PET-directed RT was associated with a more widespread pattern of metastases (increase in bone metastases and extrapelvic lymph node metastases), which is a possible indicator for an evolving tumor biology. Until now, the evolutionary history of metastatic prostate cancer of monoclonal versus polyclonal cell seeding leading to a linear versus branching pattern of metastatic spread [28] at low PSA levels remains unknown. Many genomic and nongenomic biomarkers have been investigated in $\mathrm{mPC}[29$, 30], but none of these markers are available outside of dedicated study protocols for clinical routine. On the other hand, exploratory analyses of patients with limited tumor burden according to the CHAARTED criteria revealed no OS benefit for escalated systemic therapy using either the combination of $\mathrm{ADT}+$ docetaxel [31] or ADT + enzalutamide [32] compared to ADT alone, indicating a different biology. With regard to PSA kinetics as a biomarker, we found that the median PSA-dt at the second PSMA PET-directed RT was significantly shorter than the median PSA-dt at the first PSMA PET-directed RT (5.8 versus 8.7 months, $p=0.05$ ), indicating a biologically more aggressive disease at oligoprogression after the first PSMA PET-directed RT. Furthermore, a PSA-dt $<6$ months, compared to a PSA-dt $>6$ months, showed a trend towards significance $(p=0.12)$ in multivariate analyses for a worse BPFS_1. Ost el. showed that patients with non-castrate mPCA and one metastasis plus a PSA-dt $>3$ months had a 5-year CSS rate of $100 \%$, whereas patients with a PSA-dt $<3$ months plus $>1$ metastasis had a 5-year CSS rate of only $8 \%$ [33]. There is controversy about the radiation dose, field size, and elective node irradiation when PSMA ligand PET is used for MDT of oligorecurrent mPCa. Data from the choline PET era confirmed that choline PET underestimated the extent of lymph node metastases [34], which is reflected by the fact that approximately two out of three patients treated with SBRT for pelvic lymph node metastases relapsed with lymph node metastases [25, 35], leading to a higher relapse rate than that after elective node irradiation (ENI), although the relapse rate concerning bone and visceral metastases seems to be comparable between SBRT and ENI [36]. The extent of lymph node metastases can be assessed more precisely 
by PSMA PET than by choline PET [7]. Therefore, we do not recommend ENI because the initiation of systemic therapies according to high- and low-burden disease and the corresponding prognosis do not depend on lymph node metastases, but on bone and visceral metastases [1]. In addition, other retrospective data from the PSMA PET era assessing the pattern of progression of lesion-directed RT without ENI of contralateral lymphatic drainage showed a significant increase in retroperitoneal and osseous metastases and only a very small number of contralateral pelvic recurrences [2]. These results may indicate that ENI may have been a necessary compensator for the poor detection rate of lymph node metastases of choline PET scans.

Some limitations of this study should be acknowledged. The retrospective nature has inherent limitations and might have introduced selection bias, although the presented cohort had a strict follow-up schedule and staging was performed only with PSMA ligand PET. Therefore, fewer metastases should be missed with this method than with conventional imaging and choline PET [11, 20, 35], leading to well-selected patients [37]. Moreover, the second PSMA ligand PET for restaging purposes allows assessment of the metabolic response after RT, leading to a reliable discrimination of new metastases and successfully irradiated metastases [38]. In addition, the study included a selected cohort with only high-risk and very high-risk patients. Therefore, caution should be taken when generalizing the observed results for patients with intermediate- or low-risk oligorecurrent PCa. Additionally, the sample size of 32 patients limited the statistical power, although the observed clinical results are robust and contribute significantly to the discussion of a second PSMA PET-directed MDT after curative primary therapy in a quickly changing clinical field.

\section{Conclusion}

Repeated PMSA PET-directed RT for oligorecurrent prostate cancer postponed ADT without significant toxicities. If patients are followed up closely, including PSMA PET scans, repeated PSMA PET-directed RT represents a viable treatment option for well-informed and wellselected patients.

Funding Open Access funding provided by Projekt DEAL.

\section{Compliance with ethical guidelines}

Conflict of interest C. Henkenberens, A.-K. Oehus, T. Derlin, F. Bengel, T.L. Ross, M.A. Kuczyk, S. Janssen, H. Christiansen, and C.A.J. von Klot declare that they have no competing interests.
Ethical standards This retrospective analysis was approved by the local ethics committee.

Open Access This article is licensed under a Creative Commons Attribution 4.0 International License, which permits use, sharing, adaptation, distribution and reproduction in any medium or format, as long as you give appropriate credit to the original author(s) and the source, provide a link to the Creative Commons licence, and indicate if changes were made. The images or other third party material in this article are included in the article's Creative Commons licence, unless indicated otherwise in a credit line to the material. If material is not included in the article's Creative Commons licence and your intended use is not permitted by statutory regulation or exceeds the permitted use, you will need to obtain permission directly from the copyright holder. To view a copy of this licence, visit http://creativecommons.org/licenses/by/4. $0 \%$

\section{References}

1. Cornford P, Bellmunt J, Bolla M, Briers E, De Santis M, Gross T, Henry AM, Joniau S, Lam TB, Mason MD, van der Poel HG, van der Kwast TH, Rouvière O, Wiegel T, Mottet N (2017) EAUESTRO-SIOG guidelines on prostate cancer. Part II: Treatment of relapsing, metastatic, and castration-resistant prostate cancer. Eur Urol 71:630-642

2. Soldatov A, von Klot CAJ, Walacides D, Derlin T, Bengel FM, Ross TL, Wester HJ, Derlin K, Kuczyk MA, Christiansen H, Henkenberens C (2019) Patterns of progression after ${ }^{68}$ ga-PSMALigand PET/CT-guided radiation therapy for recurrent prostate cancer. Int J Radiat Oncol Biol Phys 103:95-104

3. Kroeze SGC, Henkenberens C, Schmidt-Hegemann NS, Vogel MME, Kirste S, Becker J, Burger IA, Derlin T, Bartenstein P, Eiber M, Mix M, la Fougère C, Christiansen H, Belka C, Combs SE, Grosu AL, Müller AC, Guckenberger M (2020) Prostate-specific membrane antigen positron emission tomography-detected oligorecurrent prostate cancer treated with metastases-directed radiotherapy: Role of addition and duration of androgen deprivation. Eur Urol Focus. https://doi.org/10.1016/j.euf.2019.08.012

4. Walacides D, Meier A, Knöchelmann AC, Meinecke D, Derlin T, Bengel FM, Ross TL, Wester HJ, Derlin K, Kuczyk MA, von Klot CAJ, Christiansen H, Henkenberens C (2019) Comparison of ${ }^{68} \mathrm{Ga}$-PSMA ligand PET/CT versus conventional cross-sectional imaging for target volume delineation for metastasis-directed radiotherapy for metachronous lymph node metastases from prostate cancer. Strahlenther Onkol 195:420-429

5. Henkenberens C, Derlin T, Bengel FM, Ross TL, Wester HJ, Hueper K, Kuczyk MA, Christiansen H, von Klot CA (2018) Patterns of relapse as determined by ${ }^{68} \mathrm{Ga}$-PSMA ligand PET/CT after radical prostatectomy: Importance for tailoring and individualizing treatment. Strahlenther Onkol 194:303-310

6. Triggiani L, Alongi F, Buglione M, Detti B, Santoni R, Bruni A, Maranzano E, Lohr F, D'Angelillo R, Magli A, Bonetta A, Mazzola R, Pasinetti N, Francolini G, Ingrosso G, Trippa F, Fersino S, Borghetti P, Ghirardelli P, Magrini SM (2017) Efficacy of stereotactic body radiotherapy in oligorecurrent and in oligoprogressive prostate cancer: new evidence from a multicentric study. Br J Cancer 116:1520-1525

7. Calais J, Czernin J, Cao M, Kishan AU, Hegde JV, Shaverdian N, Sandler K, Chu FI, King CR, Steinberg ML, Rauscher I, SchmidtHegemann NS, Poeppel T, Hetkamp P, Ceci F, Herrmann K, Fendler WP, Eiber M, Nickols NG (2018) ${ }^{68}$ ga-PSMA-11 PET/CT mapping of prostate cancer biochemical recurrence after radical prostatectomy in 270 patients with a PSA level of less than $1.0 \mathrm{ng} / \mathrm{mL}$ : impact on salvage radiotherapy planning. J Nucl Med 59:230-237 
8. McCarthy M, Francis R, Tang C, Watts J, Campbell A (2019) A multicenter prospective clinical trial of ${ }^{68}$ gallium PSMA HBED-CC PET-CT restaging in biochemically relapsed prostate carcinoma: Oligometastatic rate and distribution compared with standard imaging. Int J Radiat Oncol Biol Phys 104:801-808

9. Schmuck S, Mamach M, Wilke F, von Klot CA, Henkenberens C, Thackeray JT, Sohns JM, Geworski L, Ross TL, Wester HJ, Christiansen H, Bengel FM, Derlin T (2017) Multiple time-point 68gaPSMA I\&T PET/CT for characterization of primary prostate cancer: value of early dynamic and delayed imaging. Clin Nucl Med 42:e286-e293

10. Schmuck S, Nordlohne S, von Klot CA, Henkenberens C, Sohns JM, Christiansen H, Wester HJ, Ross TL, Bengel FM, Derlin T (2017) Comparison of standard and delayed imaging to improve the detection rate of $\left[{ }^{68} \mathrm{Ga}\right]$ PSMA I\&T PET/CT in patients with biochemical recurrence or prostate-specific antigen persistence after primary therapy for prostate cancer. Eur J Nucl Med Mol Imaging 44:960-968

11. Schmuck S, von Klot CA, Henkenberens C, Sohns JM, Christiansen H, Wester HJ, Ross TL, Bengel FM, Derlin T (2017) Initial experience with volumetric ${ }^{68}$ ga-PSMA I\&T PET/CT for assessment of whole-body tumor burden as a quantitative imaging biomarker in patients with prostate cancer. J Nucl Med 58:1962-1968

12. Tosoian JJ, Gorin MA, Ross AE, Pienta KJ, Tran PT, Schaeffer EM (2017) Oligometastatic prostate cancer: definitions, clinical outcomes, and treatment considerations. Nat Rev Urol 14:15-25

13. Ost P, Reynders D, Decaestecker K, Fonteyne V, Lumen N, De Bruycker A, Lambert B, Delrue L, Bultijnck R, Claeys T, Goetghebeur E, Villeirs G, De Man K, Ameye F, Billiet I, Joniau S, Vanhaverbeke F, De Meerleer G (2018) Surveillance or metastasisdirected therapy for oligometastatic prostate cancer recurrence: A prospective, randomized, multicenter phase II trial. J Clin Oncol 36:446-453

14. Siva S, Bressel M, Murphy DG, Shaw M, Chander S, Violet J, Tai KH, Udovicich C, Lim A, Selbie L, Hofman MS, Kron T, Moon D, Goad J, Lawrentschuk N, Foroudi F (2018) Stereotactic Abative Body Radiotherapy (SABR) for oligometastatic prostate cancer: a prospective clinical trial. Eur Urol 74:455-462

15. Kneebone A, Hruby G, Ainsworth H, Byrne K, Brown C, Guo L, Guminski A, Eade T (2018) Stereotactic body radiotherapy for oligometastatic prostate cancer detected via prostate-specific membrane antigen positron emission tomography. Eur Urol Oncol $1: 531-537$

16. Decaestecker K, De Meerleer G, Lambert B, Delrue L, Fonteyne V, Claeys T, De Vos F, Huysse W, Hautekiet A, Maes G, Ost P (2014) Repeated stereotactic body radiotherapy for oligometastatic prostate cancer recurrence. Radiat Oncol. https://doi.org/10.1186/ 1748-717X-9-135

17. Eder M, Schäfer M, Bauder-Wüst U, Hull WE, Wängler C, Mier W, Haberkorn U, Eisenhut M (2012) 68Ga-complex lipophilicity and the targeting property of a urea-based PSMA inhibitor for PET imaging. Bioconjug Chem 23:688-697

18. Fendler WP, Eiber M, Beheshti M, Bomanji J, Ceci F, Cho S, Giesel F, Haberkorn U, Hope TA, Kopka K, Krause BJ, Mottaghy FM, Schöder H, Sunderland J, Wan S, Wester HJ, Fanti S, Herrmann K (2017) ${ }^{68}$ Ga-PSMA PET/CT: Joint EANM and SNMMI procedure guideline for prostate cancer imaging: version 1.0. Eur J Nucl Med Mol Imaging 44:1014-1024

19. National Cancer Institute (2020) Common Terminology Criteria for Adverse Events (CTCAE)v4.0. http://ctep.cancer.gov/ protocolDevelopment/electronic_applications/ctc.htm. Accessed 22 Dec 2020

20. Afshar-Oromieh A, Holland-Letz T, Giesel FL, Kratochwil C, Mier W, Haufe S, Debus N, Eder M, Eisenhut M, Schäfer M, Neels O, Hohenfellner M, Kopka K, Kauczor HU, Debus J,
Haberkorn U (2017) Diagnostic performance of ${ }^{68} \mathrm{Ga}$-PSMA11 (HBED-CC) PET/CT in patients with recurrent prostate cancer: evaluation in 1007 patients. Eur J Nucl Med Mol Imaging 44:1258-1268

21. Gillessen S, Attard G, Beer TM, Beltran H, Bossi A, Bristow R, Carver B, Castellano D, Chung BH, Clarke N, Daugaard G, Davis ID, de Bono J, Borges Dos Reis R, Drake CG, Eeles R, Efstathiou E, Evans CP, Fanti S, Feng F, Fizazi K, Frydenberg M, Gleave M, Halabi S, Heidenreich A, Higano CS, James N, Kantoff P, Kellokumpu-Lehtinen PL, Khauli RB, Kramer G, Logothetis C, Maluf F, Morgans AK, Morris MJ, Mottet N, Murthy V, Oh W, Ost P, Padhani AR, Parker C, Pritchard CC, Roach M, Rubin MA, Ryan C, Saad F, Sartor O, Scher H, Sella A, Shore N, Smith M, Soule H, Sternberg CN, Suzuki H, Sweeney C, Sydes MR, Tannock I, Tombal B, Valdagni R, Wiegel T, Omlin A (2018) Management of patients with advanced prostate cancer: the report of the advanced prostate cancer consensus conference APCCC 2017. Eur Urol 73:178-211

22. Morgans AK, Stockler MR (2019) Patient-reported outcomes in metastatic castration-sensitive prostate cancer in the adjuvant setting. Eur Urol Focus 5:144-146

23. Gomez-Iturriaga A, Casquero Ocio F, Ost P, Fernandez I, Rodeño E, Llarena R, Garcia-Olaverri J, Ortiz de Zarate R, Cacicedo J, Ahtamon A, Bilbao P (2019) Outcomes after a first and/or second salvage treatment in patients with oligometastatic prostate cancer recurrence detected by (18-F) choline PET-CT. Eur J Cancer Care (Engl) 28:e1309325

24. Berkovic P, De Meerleer G, Delrue L, Lambert B, Fonteyne V, Lumen N, Decaestecker K, Villeirs G, Vuye P, Ost P (2013) Salvage stereotactic body radiotherapy for patients with limited prostate cancer metastases: deferring androgen deprivation therapy. Clin Genitourin Cancer 11:27-32

25. Nørgaard M, Jensen AØ, Jacobsen JB, Cetin K, Fryzek JP, Sørensen HT (2010) Skeletal related events, bone metastasis and survival of prostate cancer: a population based cohort study in Denmark (1999 to 2007). J Urol 184:162-167

26. Gandaglia G, Karakiewicz PI, Briganti A, Passoni NM, Schiffmann J, Trudeau V, Graefen M, Montorsi F, Sun M (2015) Impact of the site of metastases on survival in patients with metastatic prostate cancer. Eur Urol 68:325-334

27. Pompe RS, Tilki D, Preisser F, Leyh-Bannurah SR, Bandini M, Marchioni M, Gild P, Tian Z, Fossati N, Cindolo L, Shariat SF, Huland H, Graefen M, Briganti A, Karakiewicz PI (2018) Survival benefit of local versus no local treatment for metastatic prostate cancer-Impact of baseline PSA and metastatic substages. Prostate 78:753-757

28. Gundem G, Van Loo P, Kremeyer B, Alexandrov LB, Tubio JMC, Papaemmanuil E, Brewer DS, Kallio HML, Högnäs G, Annala M, Kivinummi K, Goody V, Latimer C, O'Meara S, Dawson KJ, Isaacs W, Emmert-Buck MR, Nykter M, Foster C, Kote-Jarai Z, Easton D, Whitaker HC, ICGC Prostate Group (2015) The evolutionary history of lethal metastatic prostate cancer. Nature 520:353-357

29. Cucchiara V, Cooperberg MR, Dall'Era M, Lin DW, Montorsi F, Schalken JA, Evans CP (2018) Genomic markers in prostate cancer decision making. Eur Urol 73:572-582

30. Schepisi G, Brighi N, Cursano MC, Gurioli G, Ravaglia G, Altavilla A, Burgio SL, Testoni S, Menna C, Farolfi A, Casadei C, Tonini G, Santini D, De Giorgi U (2019) Inflammatory biomarkers as predictors of response to immunotherapy in urological tumors. J Oncol. https://doi.org/10.1155/2019/7317964

31. Kyriakopoulos CE, Chen YH, Carducci MA, Liu G, Jarrard DF, Hahn NM, Shevrin DH, Dreicer R, Hussain M, Eisenberger M, Kohli M, Plimack ER, Vogelzang NJ, Picus J, Cooney MM, Garcia JA, DiPaola RS, Sweeney CJ (2018) Chemohormonal therapy in metastatic hormone-sensitive prostate cancer: long-term survival 
analysis of the randomized phase III E3805 CHAARTED trial. J Clin Oncol 36:1080-1087

32. Davis ID, Martin AJ, Stockler MR, Begbie S, Chi KN, Chowdhury S, Coskinas X, Frydenberg M, Hague WE, Horvath LG, Joshua AM, Lawrence NJ, Marx G, McCaffrey J, McDermott R, McJannett M, North SA, Parnis F, Parulekar W, Pook DW, Reaume MN, Sandhu SK, Tan A, Tan TH, Thomson A, Tu E, Vera-Badillo F, Williams SG, Yip S, Zhang AY, Zielinski RR, Sweeney CJ (2019) Enzalutamide with standard first-line therapy in metastatic prostate cancer. N Engl J Med 381:121-131

33. Ost P, Decaestecker K, Lambert B, Fonteyne V, Delrue L, Lumen N, Ameye F, De Meerleer G (2014) Prognostic factors influencing prostate cancer-specific survival in non-castrate patients with metastatic prostate cancer. Prostate 74:297-305

34. Kim SJ, Lee SW (2019) Diagnostic accuracy of F18 flucholine $\mathrm{PET} / \mathrm{CT}$ for preoperative lymph node staging in newly diagnosed prostate cancer patients; a systematic review and meta-analysis. $\mathrm{Br}$ J Radiol. https://doi.org/10.1259/bjr.20190193

35. van Leeuwen PJ, Stricker P, Hruby G, Kneebone A, Ting F, Thompson B, Nguyen Q, Ho B, Emmett L (2016) (68) Ga-PSMA has a high detection rate of prostate cancer recurrence outside the pro- static fossa in patients being considered for salvage radiation treatment. BJU Int 117:732-739

36. De Bleser E, Jereczek-Fossa BA, Pasquier D, Zilli T, Van As N, Siva S, Fodor A, Dirix P, Gomez-Iturriaga A, Trippa F, Detti B, Ingrosso G, Triggiani L, Bruni A, Alongi F, Reynders D, De Meerleer G, Surgo A, Loukili K, Miralbell R, Silva P, Chander S, Di Muzio NG, Maranzano E, Francolini G, Lancia A, Tree A, Deantoni CL, Ponti E, Marvaso G, Goetghebeur E, Ost P (2019) Metastasis-directed therapy in treating nodal oligorecurrent prostate cancer: a multi-institutional analysis comparing the outcome and toxicity of stereotactic body radiotherapy and elective nodal radiotherapy. Eur Urol 76:732-739

37. Frenzel T, Tienken M, Abel M, Berliner C, Klutmann S, Beyersdorff D, Schwarz R, Krüll A, Bannas P (2018) The impact of [68Ga]PSMA I\&T PET/CT on radiotherapy planning in patients with prostate cancer. Strahlenther Onkol 194:646-654

38. Baumann R, Koncz M, Luetzen U, Krause F, Dunst J (2018) Oligometastases in prostate cancer : Metabolic response in follow-up PSMA-PET-CTs after hypofractionated IGRT. Strahlenther Onkol 194:318-324 